\title{
CONDITION MONITORING SYSTEMS FOR HYDRAULIC ACCUMULATORS - IMPROVEMENTS IN EFFICIENCY, PRODUCTIVITY AND QUALITY
}

\author{
Christian Nisters*, Dr.-Ing. Frank Bauer, Marco Brocker \\ HYDAC Technology GmbH, Industriestraße, 66280, Sulzbach/Saar, Germany \\ * Corresponding author: Tel.: +49 6897 5099555; E-mail address: christian.nisters@hydac.com
}

\begin{abstract}
This paper addresses the necessity of a correct hydraulic accumulator pre-charge pressure for the optimum performance and in some cases even the essential function of the corresponding hydraulic application.

In this context HYDAC has developed a smart product for predictive monitoring of the pre-charge pressure without any need to do a measurement on the gas side of the accumulator - the p0-Guard. The paper gives an overview on the conventional way of checking the pre-charge pressure, the function of the monitoring device and points out the benefits of a predictive monitoring of the accumulator precharge pressure. The benefits are clearly depicted by an analytical view as well as on practical example.

Keywords: Efficiency, Hydraulic accumulator, Pre-charge pressure, Predictive monitoring, $\mathrm{p}_{0}$-Guard
\end{abstract}

\section{INTRODUCTION}

In various hydraulic applications hydraulic accumulators are used for energy and performance support as well as for emergency functions. Due to the fact that the hydraulic medium is practically incompressible (and therefore unable to store energy) the hydraulic accumulator introduces the benefits of a compressible gas to the hydraulics. The capacity of energy storage is directly affected by the precharge pressure of the nitrogen gas $\left(\mathrm{p}_{0}\right)$ inside the accumulator [1]. The hydraulic accumulator consists of a separation element (bladder, piston, diaphragm) which separates the gas section from the fluid section connected to the hydraulic system (see Figure 1). HYDAC Accumulator Technology has many years of experience in research and development, design and production of hydraulic accumulators. As the only manufacturer of all four types of hydraulic accumulators HYDAC is suitable to supply all types of accumulators, from bladder accumulators and piston accumulators to diaphragm accumulators and also the metal bellows accumulators for special fields of application. The product range of HYDAC Accumulator Technology is completed by various types of accumulator accessories and safety equipment which makes the hydraulic accumulator ready for essential future requirements in automation and safety.
Hydraulic fluid Nitrogen gas

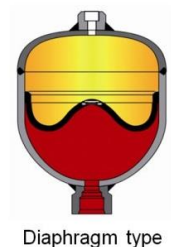

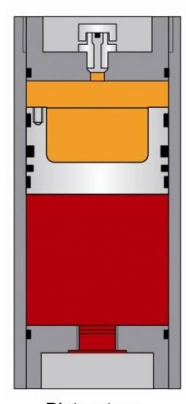

Piston type

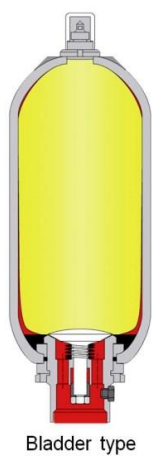

Figure 1: Different types of hydraulic accumulators

As the performance and availability of hydraulic applications is strongly depending on the correct function of the hydraulic accumulator the correct pre-charge pressure condition is essential. Illustrated using the example of a hydraulic press application the pre-charge pressure of the accumulator is affecting the performance of the press in both quality and quantity of the output product. 
This paper first gives an introduction to the relation between pre-charge pressure and the usable energy in an analytical way as well as on a simulation example. In this context the importance of a correct pre-charge pressure condition is outlined. Furthermore the risks of conventional methods of checking the pre-charge pressure and the benefits of the predictive approach by the implementation of the $\mathrm{p}_{0}$-Guard are described.

\section{THEORETICAL RELATION BETWEEN PRE-CHARGE PRESSURE AND USABLE ENERGY}

The hydraulic energy supplied to the accumulator is going to be supplied to the gas as pressurevolume works:

$W=-\int p d V$

It is stated, that most relevant hydraulic applications are pressure controlled. Therefore in the following we focus on the energy/performance potential of a hydraulic accumulator under the restriction of a fixed operational pressure range. This means that the operating pressure varies between the minimum pressure $p_{1}$ and the maximum pressure $p_{2}$. In this context Figure 2 depicts the terms of usable and non-usable energy in the $\mathrm{p}-\mathrm{V}$-diagram.

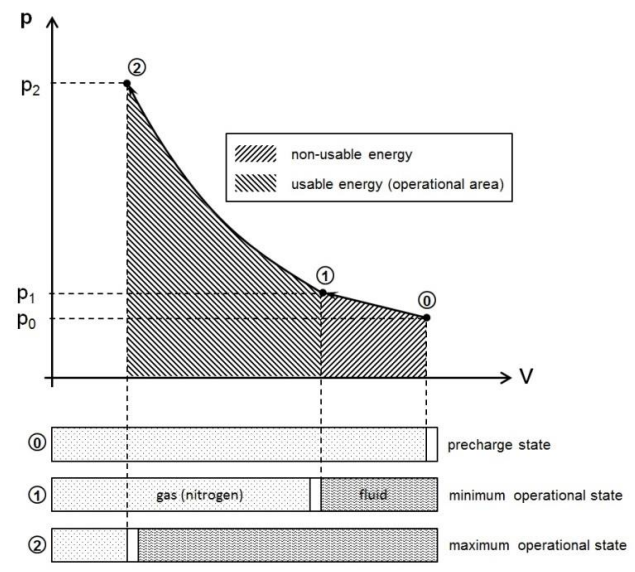

Figure 2: Operating range of a hydraulic accumulator supporting a pressure controlled system

Under the assumption of an ideal gas there are two limiting cases how to describe the thermodynamic behavior of a hydraulic accumulator:
- Isothermal

- Adiabatic

The energy equation for isothermal change of state

$W_{12, \text { iso }}=p_{1} \cdot V_{1} \cdot \ln \left(\frac{p_{2}}{p_{1}}\right)$

with an isothermal compression from state 0 to 1

$V_{1}=\frac{p_{0}}{p_{1}} \cdot V_{0}$

shows a direct proportional relation between the pre-charge pressure $\mathrm{p}_{0}$ and the usable energy in the operational range:

$W_{12, i s o}=p_{0} \cdot V_{0} \cdot \ln \left(\frac{p_{2}}{p_{1}}\right)$

For adiabatic change of state the corresponding energy equation shows the same relation:

$W_{12, a d i}=p_{0} \cdot \frac{V_{0}}{k-1} \cdot\left[\left(\frac{p_{2}}{p_{1}}\right)^{\frac{k-1}{k}}-1\right]$

The energy quotient $\beta$ is introduced in relevant literature on the calculation of hydropneumatic accumulators as the ratio between usable energy and a $\mathrm{pV}$-product representing the given energy capacity of the accumulator [2]. For the considerations in this paper the energy quotient is stated as:

$\beta=\frac{W}{V_{0} \cdot p_{2}}$

Under the assumption of an ideal gas Figure 3 and Figure 4 show the characteristic curves of the energy quotient as a function of the operating pressure ratio $\mathrm{p}_{1} / \mathrm{p}_{2}$ in dependence of the loss of pre-charge pressure, normalized to the ratio $\mathrm{p}_{0} / \mathrm{p}_{1}$.

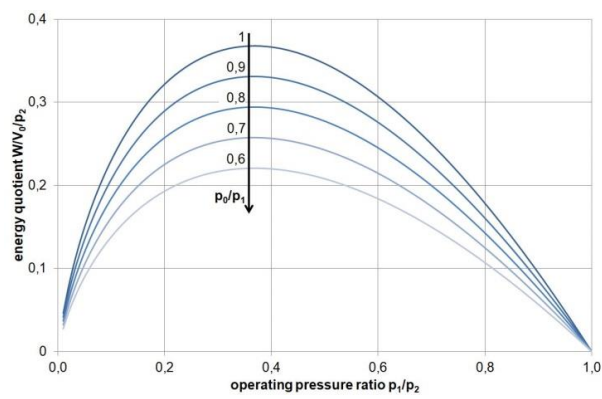

Figure 3: Energy quotient vs. operating pressure ratio (isothermal change of state) 


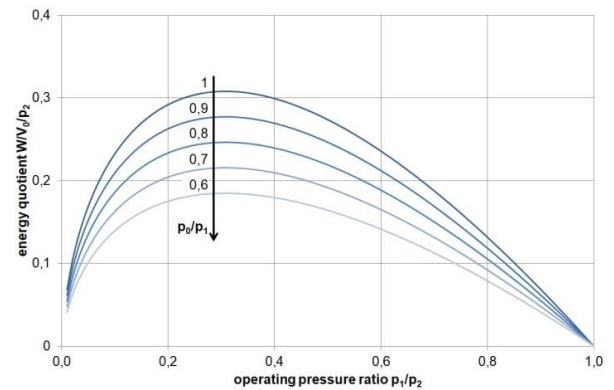

Figure 4: Energy quotient vs. operating pressure ratio (adiabatic change of state)

The figures above show an optimum operating pressure ratio $\mathrm{p}_{1} / \mathrm{p}_{2}=0,368$ for an isothermal change of state and 0,308 for an adiabatic change of state. As already shown in Equation 4 and Equation 5 the loss of pre-charge pressure $\mathrm{p}_{0} / \mathrm{p}_{1}$ reduces the energy quotient (and the usable energy of the accumulator) in a direct proportional behavior. For this reason it is mandatory to check the pre-charge pressure continuously during the operation, otherwise it leads to an inefficient use of the accumulator.

\section{EFFICIENCY DECREASE BY PRE- CHARGE LOSS}

In the following section the effects of a precharge pressure loss are shown by a dynamic simulation, exemplary on an energy supporting accumulator for the hydraulics of a tool clamping system. The tool clamping system is driven by an auxiliary HYDAC Compact Power Unit CO1. The corresponding hydraulic circuit diagram is shown in Figure 5.

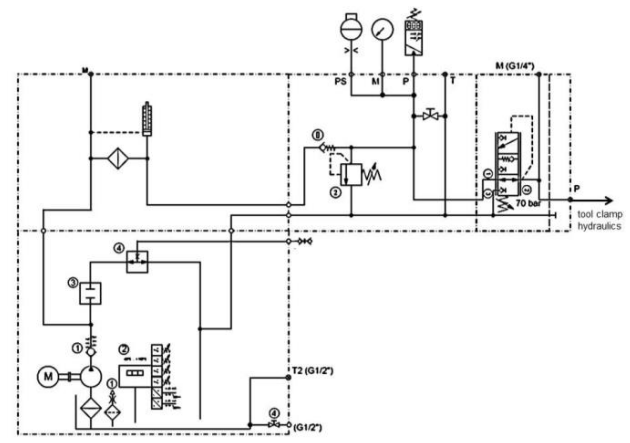

Figure 5: Hydraulic circuit diagram of HYDAC Compact Power Unit CO1
In terms of energy efficiency the pump of the power unit is controlled by an electronic pressure switch to realize a hydraulic accumulator charging function. When the accumulator pressure drops below a minimum pressure $\mathrm{p}_{1}=$ 100 bar the pump charges the accumulator up to a maximum pressure $p_{2}=150$ bar. The charged accumulator supports the hydraulics of the tool clamp as long as the pressure drops below $p_{1}$ again. In this case the energy (volume) of one accumulator filling is sufficient to carry out four working cycles of the tool clamp.

As already shown in section 2 the usable energy of an accumulator decreases with a decreasing pre-charge pressure. A real gas simulation with HYDAC in-house Accumulator Simulation Program ASP illustrates this for the given application example of a tool clamp.
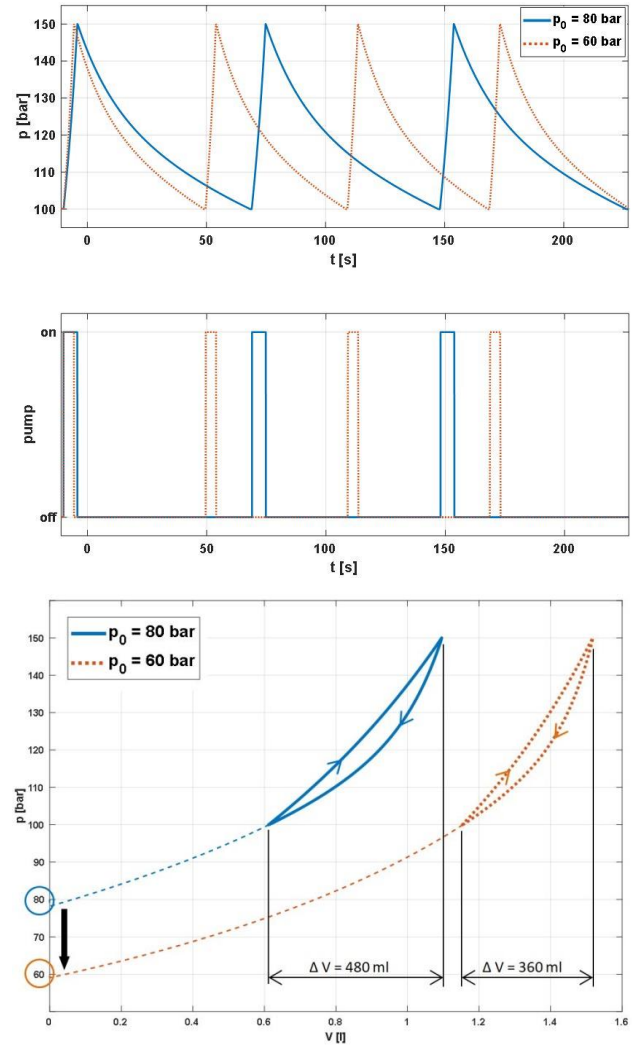

Figure 6: Simulation study of volume/energy capacity at decreased pre-charge pressure

Due to a $25 \%$ pre-charge loss from 80 bar to 60 bar the simulation results in Figure 6 predict a limitation from four to three working cycles 
operated by one accumulator filling. Concerning the operation of the power unit this means that the pump switch-on frequency increases by $25 \%$. Due to increased efficiency losses the temperature of the power unit increases. This has an effect on:

- Pump \& Valves:

Increased mechanical wear due to increased operation cycles.

- Seals:

Increased ageing due to increased operating temperatures (pump shaft seal).

- Fluid:

Increased ageing due to increased operating temperatures.

The following Table 1 gives an overview on the simulation parameters.

Table 1: Parameters of the simulation

\begin{tabular}{ll}
\hline Parameter & Value \\
\hline Max. accumulator pressure $p_{2}$ & $150 \mathrm{bar}$ \\
Min. accumulator pressure $p_{1}$ & $100 \mathrm{bar}$ \\
Pre-charge pressure $p_{0}$ & $80 \mathrm{bar}$ \\
Accumulator volume & 2,81 \\
Displacement volume & $120 \mathrm{ml} / \mathrm{cycle}$ \\
Constant pump flow rate & $51 / \mathrm{min}$ \\
\hline
\end{tabular}

\section{MONITORING THE PRE-CHARGE PRESSURE}

There are two main reasons to illustrate why a correct pre-charge pressure is so important:

- Important for function and performance of the system - to ensure the optimal accumulator performance in the operating pressure range and thus maintain the machine output.

- Important for availability of the system - to avoid destruction of the accumulator's separating element (bladder, diaphragm, sealing system of the piston) due to a permanent malfunction and thus optimise the machine service life.

The most conventional way to check the precharge pressure of a hydraulic accumulator is to measure the pressure on the gas side. The check can be carried out by permanent devices like pressure gauges or pressure transducers or by non-permanent devices like the HYDAC charging and testing unit FPU. Some major examples of conventional ways to check the pre- charge pressure by permanent pressure gauges are given in Figure 7.

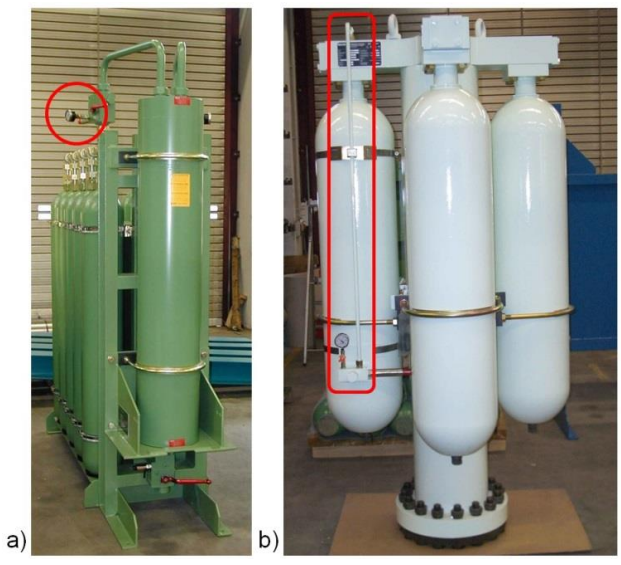

Figure 7: Examples on conventional ways to check the pre-charge pressure

On the one hand the check on the gas side is the easiest and most direct measurement method, e.g. the use of gauges gives a direct and visual indication of the gas pressure. But on the other hand there are some disadvantages and risks which should be considered:

- A comfortable accessibility of the gas side to carry out the measurement is not always ensured. It may even be necessary to use a ladder to reach the gas side of the accumulator (see Figure 7 a).

- By using permanent gauges or pressure sensors the risk of potential leakage points on the gas side has to be taken into account. In terms of better visibility the pressure gauges may be installed at eye level of the operating staff (see Figure 7 b). The additional piping increases the essential costs and further the technical risk of leakage.

- The accumulator fluid side has to be nonpressurized and thermal stabilized during the pre-charge check in order to get a representative and comparable measurement result.

\section{5. $P_{0}$-GUARD}

The preventive maintenance strategy already described leads to excessive maintenance and machine downtimes and is therefore quite time and cost intensive for the operator. 
In this context HYDAC has developed a smart product for predictive monitoring of the accumulator pre-charge pressure without any need to measure the pressure on the gas side - the $\mathrm{p}_{0}$-Guard EDS 3400 (Figure 8). By monitoring and evaluating the oil side pressure gradients the $\mathrm{p}_{0}$-Guard detects any significant drop of the precharge pressure and activates a output signal in case of a critical pre-charge value.

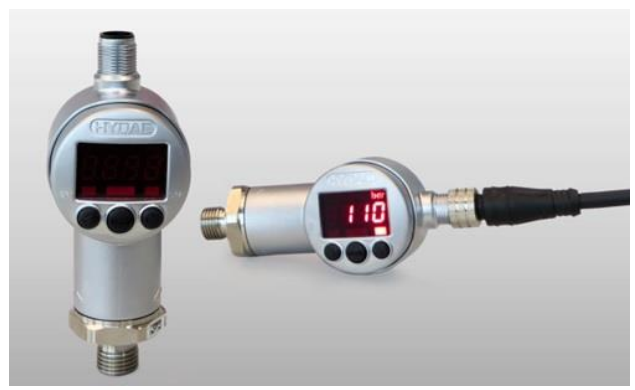

Figure 8: HYDAC $\mathrm{p}_{0}$-Guard

\subsection{Measurement principle}

The measurement principle of the $p_{0}$-Guard is based on the physical conditions of the different bulk modulus of a hydraulic fluid / system and the gas medium inside the accumulator. The physical context of the measurement principle is shown in Figure 9. According to [3] the gas pressure has to be at a value of $p \approx 10^{4}$ bar or higher to reach the same bulk modulus as the bulk modulus of a hydraulic fluid. Due to the fact that in common hydraulic operating pressure areas the bulk modulus of the hydraulic system is much higher than the bulk modulus of gas, there is a significant gradient change in the characteristic curve on pressurizing and depressurizing the accumulator.

$K_{\text {hydr. }} \gg K_{\text {gas }}$

With regard to the accumulator fluid side pressure this gradient change occurs during depressurization when the separation element sets down on the fluid side bottom of the accumulator. The related pressure is called closing pressure $\mathrm{p}_{0}$ ' and is directly dependent on the gas pre-charge pressure $\mathrm{p}_{0}$. At pressures lower than the closing pressure the accumulator gas pressure is not any more supporting the hydraulic system and the bulk modulus of the hydraulic fluid $K_{h y d r}$. is defining the system stiffness. The value of $\mathrm{p}_{0}$ ' is detected by the $\mathrm{p}_{0}$-Guard on every discharge process and the deviation from a reference $\mathrm{p}_{0}$ '-value is monitored.
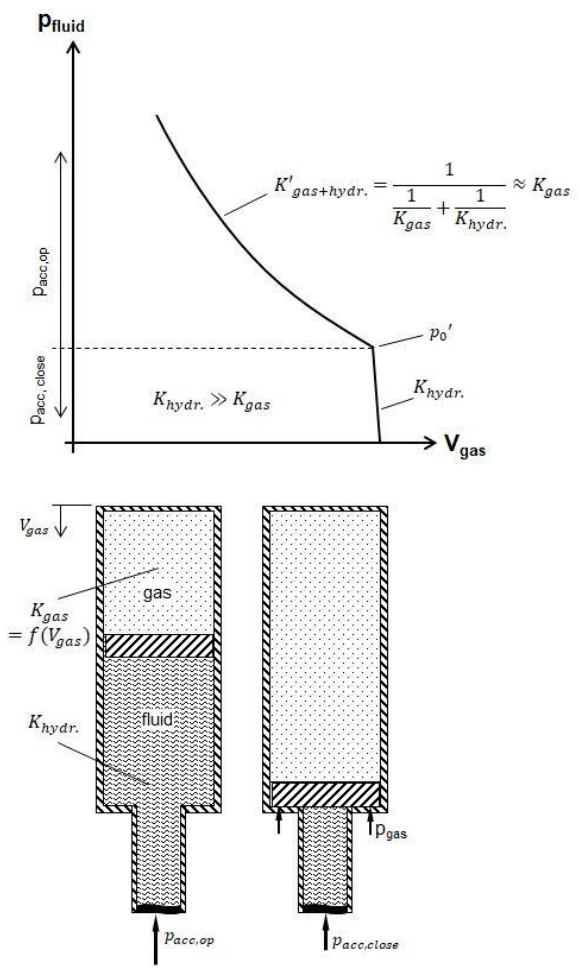

Figure 9: Measurement principle of the $\mathrm{p}_{0}$-Guard

\subsection{Validation}

The function, reliability and stability of the $\mathrm{p}_{0}$-Guard algorithm were validated in various tests at HYDAC in-house test department. Figure 10 gives an overview over the functional tests carried out to validate the accuracy and reliability of the $\mathrm{p}_{0}$-Guard on detecting the closing pressure under different discharge flow rates. On this test setup a piston accumulator with a pre-charge pressure $\mathrm{p}_{0}=80$ bar was installed on a test rig with a $\mathrm{p}_{0}$-Guard next to the accumulator. The result shows that the $\mathrm{p}_{0}$-Guard reliably detects the closing pressure at low as well as at high discharge rates. Even on high discharge flow rates with only a slight change in pressure gradient the $\mathrm{p}_{0}$-Guard is able to detect the closing pressure with a high accuracy (see Figure 10 b). 


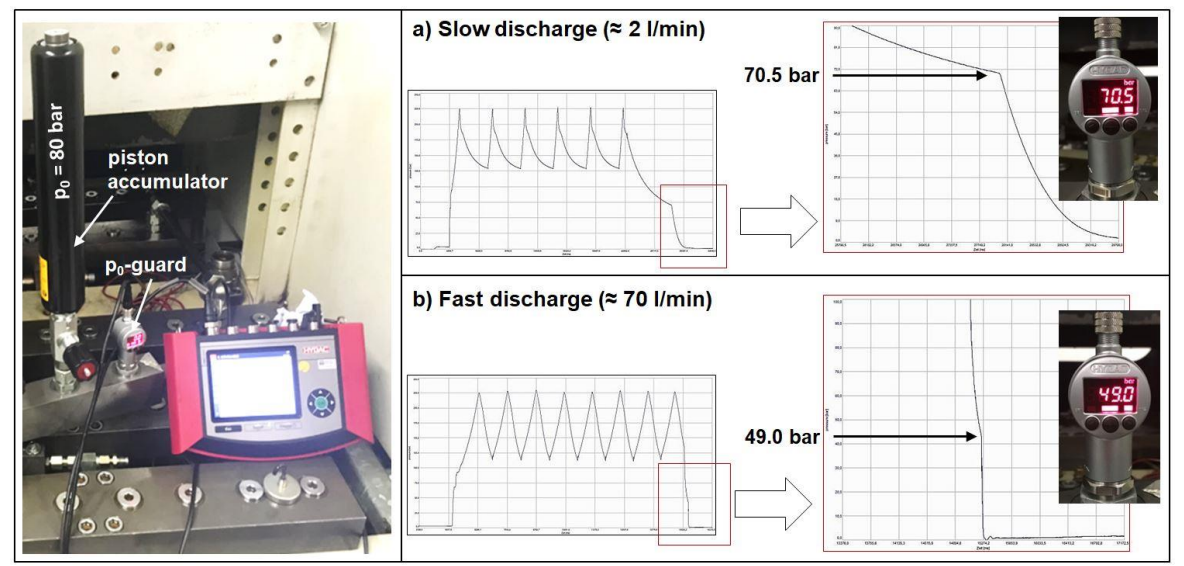

Figure 10: Validation test of the $\mathrm{p}_{0}$-Guard

It can be noticed that in both discharge processes (at slow discharge $\mathrm{p}_{0}{ }^{\prime}=70.5 \mathrm{bar}$; at fast discharge $\mathrm{p}_{0}{ }^{\prime}=49.0 \mathrm{bar}$ ) the value differs in general from the static pre-charge setting of the accumulator. This can be explained by the thermodynamic effects during accumulator discharge. On discharging the accumulator the compressed gas inside the accumulator expands and cools down the nitrogen and its surrounding. Depending on the dynamics of this change of state the closing pressure deviates more or less from the (static) pre-charge pressure [4].

This effect is examined separately on a measurement series shown in Figure 11. In this test setup a hydraulic accumulator is discharged with different flow rates under the conditions of a constant ambient temperature and a constant pre-charge pressure. The results show a nearly linear dependence between the discharge flow rate and the change ratio of the closing pressure. For a proper installation of the $\mathrm{p}_{0}$-Guard it is recommended to keep the discharge flow rate of the accumulator nearly constant on each precharge pressure detection cycle. In the simplest way by a separate bypass valve with a fixed throttle setting - what is already given in most industrial applications.

In another test setup like shown in Figure 12 five accumulators with descending pre-charge pressures from 100 bar to 80 bar were installed in parallel on a test rig. On discharging the test rig it is shown, that the $\mathrm{p}_{0}$-Guard detects the lowest closing pressure on the rig. Implied that there are several accumulators with the same nominal pre-
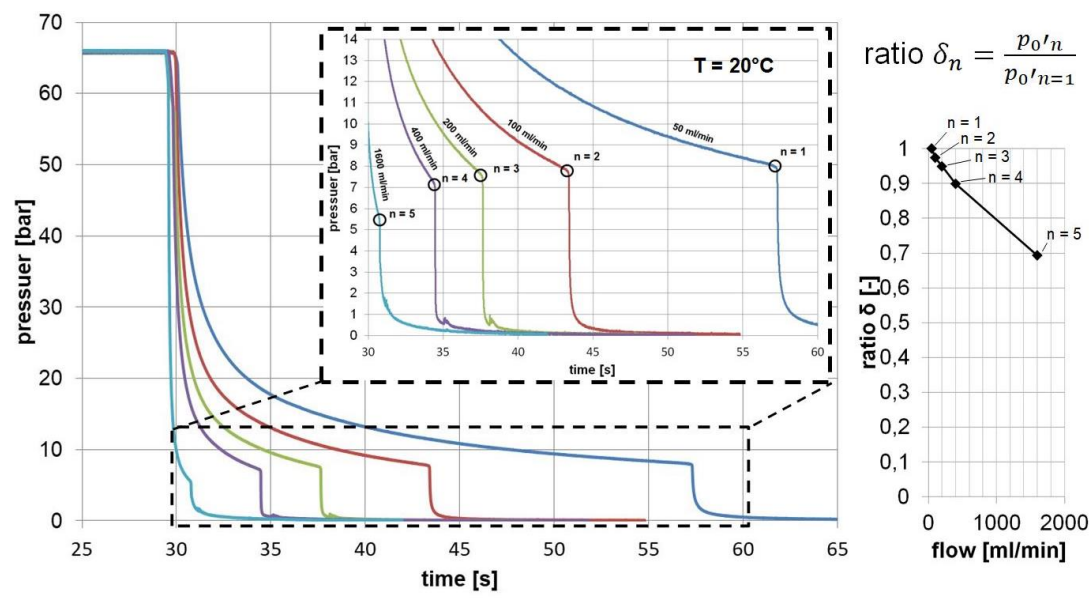

Figure 11: Study on discharge flow rate affecting the closing pressure 


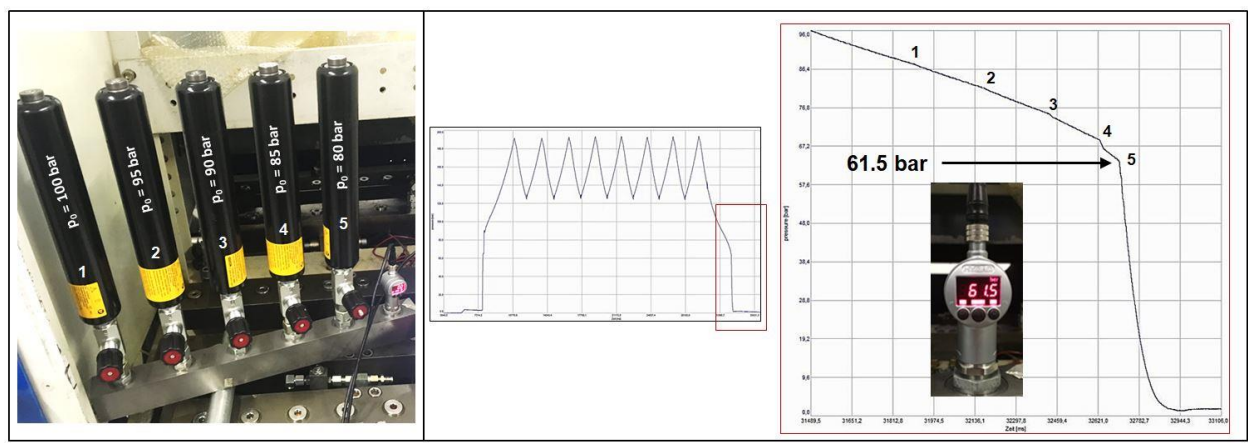

Figure 12: Validation test of the $\mathrm{p}_{0}$-Guard (multiple accumulators)

charge pressure installed on a hydraulic system, the test results show that it is possible to monitor the overall status of the accumulators pre-charge pressure with only one $\mathrm{p}_{0}$-Guard.

\subsection{Product connectivity}

To realize the detection of the closing pressure HYDAC has developed a monitoring algorithm which works even stable under the influence of disturbances like ripples or shocks on the hydraulic pressure signal. Due to the fact, that the $\mathrm{p}_{0}$-Guard is based on the hardware of a HYDAC pressure switch, the user can benefit from the advantages of a long term proven product as well as a high sampling rate (which is essential for accurate function of the implemented algorithm).

The monitoring function of the $\mathrm{p}_{0}$-Guard can either be realized in the standard switching mode or IO-Link mode. In the switching mode the output for pre-charge pressure monitoring switches off when the detected closing pressure drops below the defined minimum value. In the IO-Link mode the $\mathrm{p}_{0}$-Guard is able to communicate bi-directional with the connected IO-Link master. The master is able to change setting parameters or to read the relevant values. Beside its main function of monitoring the precharge pressure the $\mathrm{p}_{0}$-Guard has an additional output, which can either be used as a switching output for an accumulator charging function or as an analog output for the actual hydraulic pressure signal.

\section{Po-GUARD IMPLEMENTED IN HYDAC APPLICATION}

As a manufacturer of hydraulic accumulators, HYDAC of course uses the benefits of accumulators in their own production plants. Since the company's own requirements on efficiency, productivity and quality are very high, HYDAC uses the $\mathrm{p}_{0}$-Guard on most accumulators operated in their production plants. This gives HYDAC the possibility to monitor the actual precharge condition of all hydraulic accumulators, ensuring always the optimum performance. Furthermore it is now possible to generate historical trend data from which predictive data and maintenance forecasts are derived.

The benefits are shown by an example of a hydraulic clamping system working in a HYDAC production plant (see Figure 13).

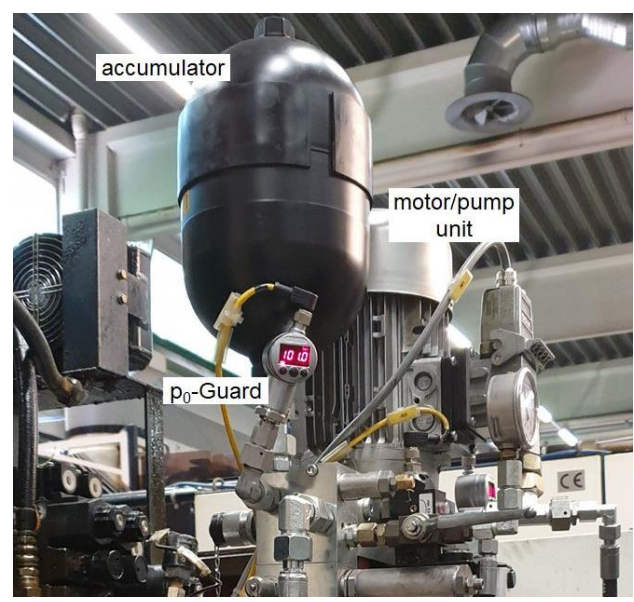

Figure 13: HYDAC Compact Power Unit CO1

The hydraulic functions driven by an auxiliary power unit are the chuck clamping, table clamping and pallet clamping (see Figure 14). 


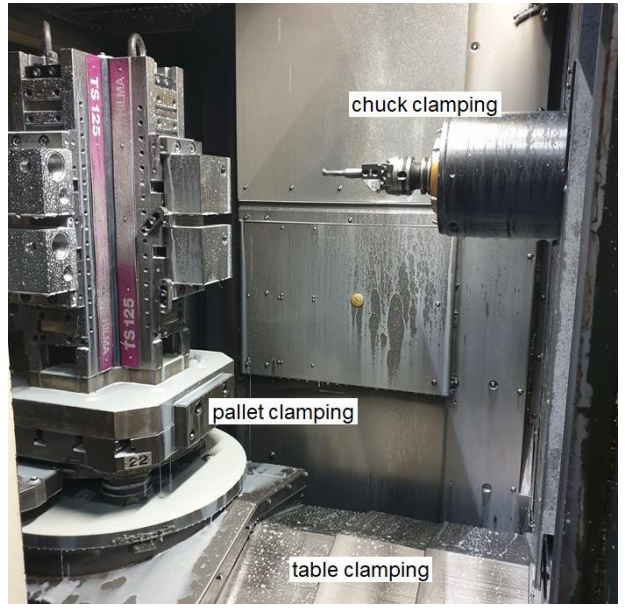

Figure 14: Hydraulic clamping functions

As a standard pressure switch only controls the accumulator charging function, the $\mathrm{p}_{0}$-Guard replaces this function and additionally introduces the pre-charge monitoring function.

The pressure curves during the standard working cycles (Figure 15) show that there is a periodic volume/energy consumption of the hydraulic clamping functions supported by the accumulator. On time periods when the accumulator support is not needed or even on machine downtimes (e.g. maintenance) the closing pressure is automatically detected and monitored by the $\mathrm{p}_{0}$-Guard.

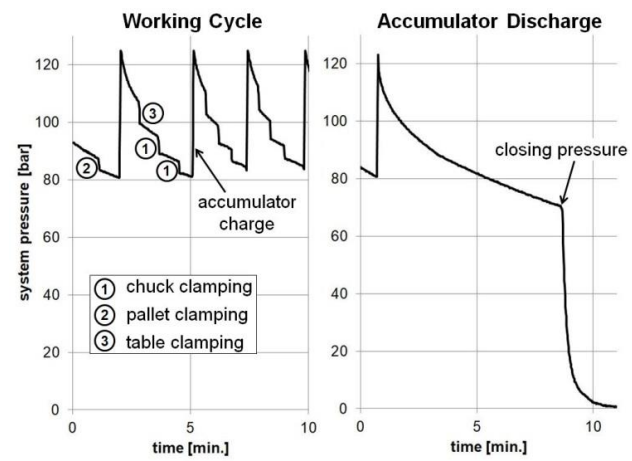

Figure 15: Pressure curves of clamping system

Due to the fact that the $\mathrm{p}_{0}$-Guard is connected to the company network via IO-Link, the detected closing pressures are periodically stored on a server. In this context Figure 16 shows the trend data of the $\mathrm{p}_{0}$ ' detected on every discharge process, collected over a period of 21 weeks.

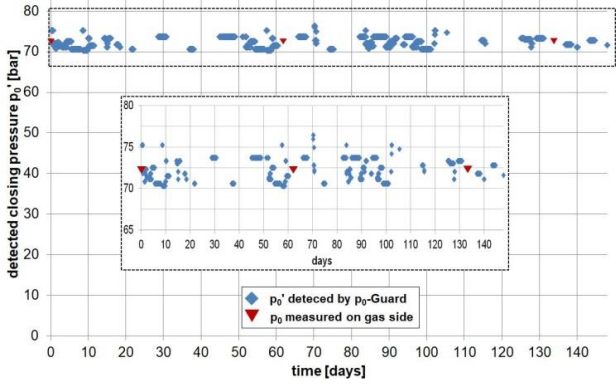

Figure 16: Detected closing pressure - trend data

Depending on the the slightly varying boundary conditions like ambient/fluid temperatures the detected closing pressures are stably scattering between 71 bar and 74 bar. For validation of the results a regular pre-charge check on the gas side confirms that there is no significant pre-charge loss on the hydraulic accumulator. So the given example shows that the energy supporting function of the accumulator is still ensured and there is no need for any pre-charge pressure service upcoming.

\section{CONCLUSION AND OUTLOOK}

This paper points out the importance of a correct accumulator pre-charge pressure condition and its impact on efficiency, productivity and quality of the hydraulic application. In this context the $\mathrm{p}_{0}$-Guard provides a smart monitoring tool for the pre-charge pressure, which can be used as standalone device as well as embedded in an industrial network system. Compared to the conventional methods to check the pre-charge pressure the $\mathrm{p}_{0}{ }^{-}$ Guard offers a number of major advantages / benefits like:

- Installation on the fluid side of the accumulator. So it is easy to retrofit and install without any need to access the gas side of the accumulator. In the easiest way the existing HYDAC pressure switch can be exchanged by the $\mathrm{p}_{0}$-Guard. This is even important in terms of accessibility, leakage and approval.

- No need to wait for thermal stabilization of the accumulator after discharge. Depending on the operating cycle and the size of the accumulator this process can take up to 30 minutes to stabilize. The $\mathrm{p}_{0}$-Guard detects the pre-charge pressure loss directly after a defined discharge. 
- The algorithm of $\mathrm{p}_{0}$-Guard works independent on the accumulator type and therefore can be used for diaphragm, metal bellow, bladder and piston accumulators also including backup gas bottles.

- The $p_{0}$-Guard works on hydraulic circuits with multiple accumulators in parallel. The lowest pre-charge pressure is detected.

- Predictive planning of maintenance intervals to support and optimize a preventive maintenance philosophy.

\section{NOMENCLATURE}

\begin{tabular}{|c|c|c|}
\hline$W$ & Energy (pressure-volume works) & {$[\mathrm{J}]$} \\
\hline$\beta$ & Energy quotient & {$[-]$} \\
\hline$k$ & Specific heat ratio of $\mathrm{N} 2$ & {$[-]$} \\
\hline$V_{0}$ & $\begin{array}{l}\text { Accumulator effective gas } \\
\text { volume }\end{array}$ & {$\left[\mathrm{m}^{3}\right]$} \\
\hline$p_{1}$ & Minimum operating pressure & [bar] \\
\hline$p_{2}$ & Maximum operating pressure & [bar] \\
\hline$V_{1}$ & Accumulator gas volume at $p_{1}$ & {$\left[\mathrm{~m}^{3}\right]$} \\
\hline$V_{2}$ & Accumulator gas volume at $p_{2}$ & {$\left[\mathrm{~m}^{3}\right]$} \\
\hline$V_{\text {gas }}$ & Accumulator gas volume & {$\left[\mathrm{m}^{3}\right]$} \\
\hline$p_{\text {gas }}$ & Accumulator gas pressure & [bar] \\
\hline$p_{a c c, o p}$ & $\begin{array}{l}\text { Hydraulic pressure on operating } \\
\text { accumulator }\end{array}$ & [bar] \\
\hline$p_{\text {acc,close }}$ & $\begin{array}{l}\text { Hydraulic pressure on } \\
\text { accumulator non-operating/closed }\end{array}$ & [bar] \\
\hline$p_{0}$ & $\begin{array}{l}\text { Accumulator pre-charge pressure } \\
\text { at } 20^{\circ} \mathrm{C}\end{array}$ & [bar] \\
\hline$p_{0}^{\prime}$ & Accumulator closing pressure & [bar] \\
\hline$K_{\text {hydr. }}$ & $\begin{array}{l}\text { Bulk modulus of hydraulic } \\
\text { fluid/system }\end{array}$ & {$[\mathrm{Pa}]$} \\
\hline$K_{\text {gas }}$ & Bulk modulus of gas & {$[\mathrm{Pa}]$} \\
\hline$K_{\text {gas }+h y d r .}^{\prime}$ & $\begin{array}{l}\text { Superposed bulk modulus of gas } \\
\text { and fluid }\end{array}$ & {$[\mathrm{Pa}]$} \\
\hline$\Delta p_{0}$ & Loss of pre-charge pressure & [bar] \\
\hline$\Delta p_{0}^{\prime}$ & Loss of closing pressure & [bar] \\
\hline
\end{tabular}

\section{REFERENCES}

[1] Korkmaz F. (1981) Hydrospeicher als Energiespeicher. Springer, Berlin.

[2] Rotthäuser S. (1993) Verfahren zur Berechnung und Untersuchung hydropneumatischer Speicher. Dissertation, RWTH Aachen
[3] Murrenhoff H. (2011) Grundlagen der Fluidtechnik Teil 1:Hydraulik. 6. neu bearbeitete Auflage

[4] Rist, D. (1996) Dynamik realer Gase. 1. Auflage 